$327^{2} / 26 / 58-R-65-851$
$2 / 25$

CONF-695-5

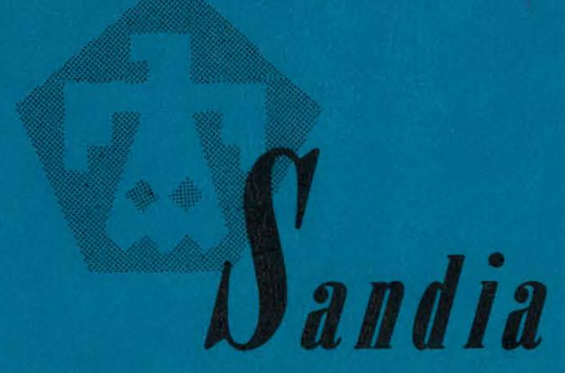

Corporation

R B P R I N T

PULSE STRENGTH OF HIGH POLYMERS

\author{
PATEIT GLEARANCE OBTAINED, RELEASE TE \\ ThE PUGLC IS APPROVED, PROGEOURES \\ by \\ O Milton, J B Allyn, \\ $\mathrm{L} \mathrm{J}$ Seligman, and $\mathrm{J} \mathrm{L}$ Wentz
}

JANUARY 1965 


\section{DISCLAIMER}

This report was prepared as an account of work sponsored by an agency of the United States Government. Neither the United States Government nor any agency Thereof, nor any of their employees, makes any warranty, express or implied, or assumes any legal liability or responsibility for the accuracy, completeness, or usefulness of any information, apparatus, product, or process disclosed, or represents that its use would not infringe privately owned rights. Reference herein to any specific commercial product, process, or service by trade name, trademark, manufacturer, or otherwise does not necessarily constitute or imply its endorsement, recommendation, or favoring by the United States Government or any agency thereof. The views and opinions of authors expressed herein do not necessarily state or reflect those of the United States Government or any agency thereof. 


\section{DISCLAIMER}

Portions of this document may be illegible in electronic image products. Images are produced from the best available original document. 
Presented at: U. S. - U. K. EIVR-10 Conference, Aldermaston, England. October $19-23,1964$ by R. R. Sowell.

Issued by

Sandia Curpuration,

a prime contractor to the

United States Atomic Energy Commission

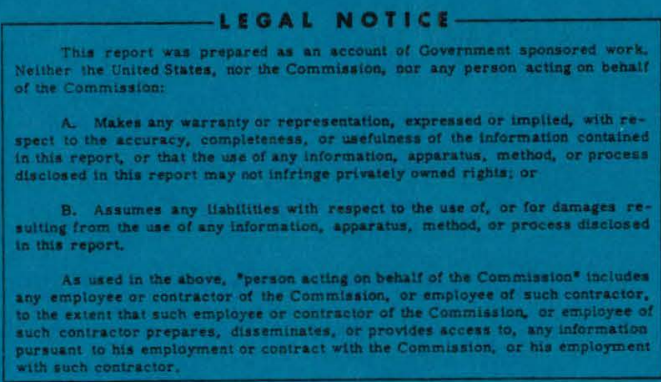

Printed in USA. Price $\$ 1,00$. Available from the Clearinghouse for Federal Scientific and Technical Information, National Bureau of Standards, U. S. Department of Commerce, Springfield, Virginia 
SC-R-65-851

METALS, CERAMICS, AND MATERIALS

TID-4500(37th Edition)

\section{SANDIA CORPORATTON REPRINT}

PULSE STRENGTH OF HIGH POLYMERS

by

O. Milton, J. B. Allyn,

L. J. Seligman, and J. L. Wentz

January 1965

f 


\section{ABSTRACT}

Force fields from a $20 \mu \mathrm{sec}$ electrical pulse and a cylindrical shock front obtained from an exploded wire were applied to high polymers to study mechanism of breakdown and intrinsic strength. Preliminary results indicate that an inverse relationship exists between mechanical pulse strenglh and electrical pulse strength, that a filler improves electrical pulse resistance of an epoxy resin, and that the intrinsic clcctrical strunglh we ru pisy resin is at least $8 \times 10^{6} \mathrm{v} / \mathrm{cm}$.

\section{ACKNOWLEDGMENT}

The authors are grateful to Messrs. F. F. Francis, C. W. Buols, and L. L. Lodge for help in preparing samples and conducting the test discussed in this report. 


\section{TABLE OF CONTENTS}

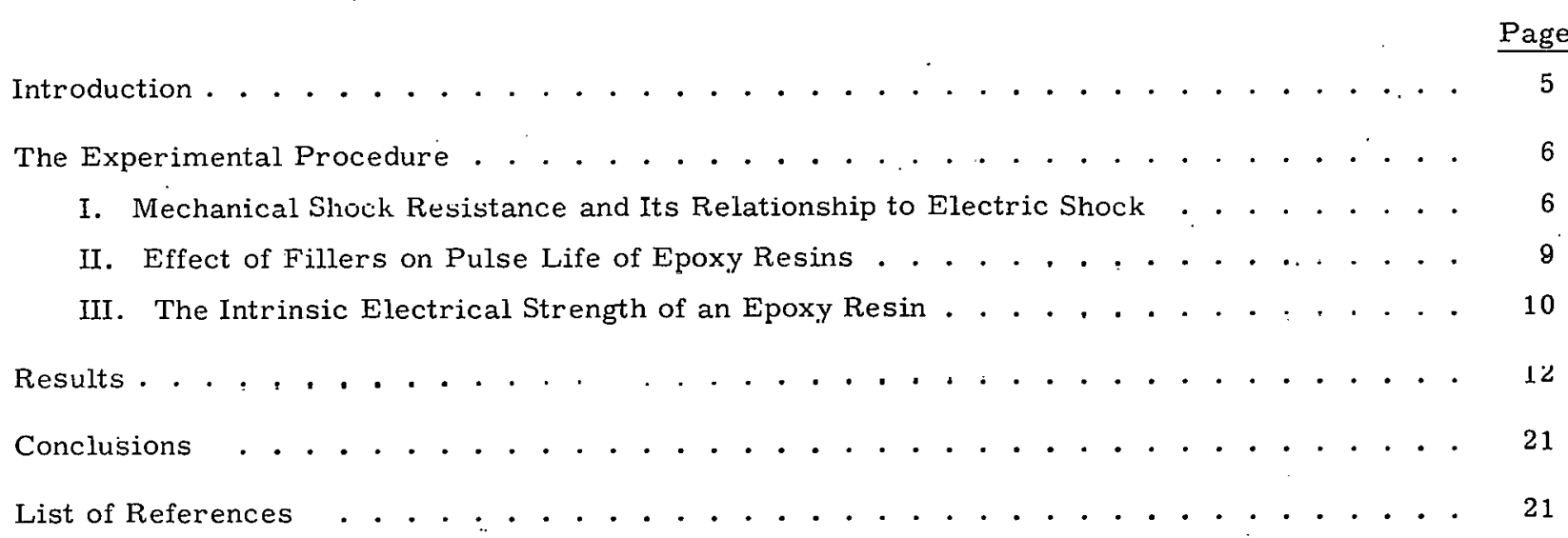




\section{LIST OF ILLUŚTRATIONS}

$\underline{\text { Figure }}$

$\underline{\text { Page }}$

1. Exploding Wire Test Geometry With Gas Checks, Wire Previously Exploded . . . . 6

2. Schematic of Exploding Wire Circuit . . . . . . . . . . . . . . . . . . . . . . 7

3. Typical Voltage and Current Characteristic, Obtained From Adiprene-L Tested

With Gas Checks at 2000 Volts . . . . . . . . . . . . . . . . . . . . . . . 8

4. An Unfilled Sample and a Cross-Sectioned Filled Sample which Have Been Tésled.

Also Shnwn is a Sample of the Glass Filler. . . . . . . . . . . . . . . . . . . . . s

5. Contoured Dielectric Test Sample . . . . . . . . . . . . . . . . . . . . . . . 10

6. Sample for Pin Tests . . . . . . . . . . . . . . . . . . . . . . 11

7. Exploded Wire in Sylgard 182, $35 \mathrm{X}$. . . . . . . . . . . . . . . . . . . . . . 13

8. Exploded Wire in Adiprene-L, $35 \mathrm{X}$. . . . . . . . . . . . . . . . . . . . . . 13

9. Exploded Wirc in SRIR, 35x . . . . . . . . . . . . . . . . . . . . . . . . . . 14

10. Wire Exploding in Sylgard 182. Framing Rate $=250 \times 10^{3} / \mathrm{sec}$. . . . . . . . . . 15

11. Wire Exploding in SRIR. Framing Rate $=250 \times 10^{3} / \mathrm{sec}$. . . . . . . . . . . . . 15

12. Thermal Diffusivity Versus Temperature for Four Casting Resins . . . . . . . . . 17

13. Electrical Pulse Results for the Filler Study . . . . . . . . . . . . . . . . . 18

14. Distribution of Pulse Dielectric Strengths for SRIR. Cuntoured Sample, 0.030 Inch

Thick . . . . . . . . . . . . . . . . . . . . . . . . . . .

LIST OF TABLES 


\title{
PULSE STRENGTH OF HIGH POLYMERS
}

\author{
Introduction
}

This report deals with three problems: the relationship between mechanical and electrical pulse strengths of a casting resin, the effect of a filler on the electrical pulse resistance of an epoxy resin, and the determination of the intrinsic electrical strength of an epoxy resin. Since this material is taken from studies still in progress, results and conclusions presented here are not final.

One of the oldest theories of electrical breakdown in a dielectric suggests that the failure mechanism is purely mechanical in nature, that is, the electrical field causes mechanical rupture through which discharge occurs. Although this theory applies in certain instances, it is not accepted in general. However, study of the electrical breakdown path obtained with a pulsed divergent field suggests that mechanical failure may be important in stopping a partial breakdown. ${ }^{2}$ In the first study discussed, four casting resins subjected to pulsed mechanical and electrical force fields were compared to more clearly define the relationship between mechanical and electrical pulse breakdown.

If mechanical breakdown results in electrical breakdown through the propagation of minute cracks, then it seems that certain fillers in a cast epoxy might serve as termination points for a crack thus improving pulse resistance of an epoxy. In the second study, glass balls of varying size and composition were used as a filler in a modified epoxy to see if this hypothesis were true.

Knowledge of the intrinsic breakdown voltage of insulating materials enables comparison with theory and allows correction for geometrical considerations in design applications. It has been assumed that if the electrical strength is related by a constant to the thickness of insulation over a reasonable range, then the intrinsic strength is given by the constant relating the two variables. However, it is difficult to obtain this constant except for very thin thicknesses or over a limited thickness range. Some materials, especially casting resins are difficult to polymerize in the form of thin films.

At least two other approaches to obtaining the intrinsic strength may be applied. The first, a statistical method indicating an extreme value or the value that a flaw-free sample might have, is useful if the test method utilizes something other than a micro-volume of the material subjected to maximum field. ${ }^{*}$ The second method utilizes a micro-volume of material for test in a nonuniform field. In each case the mathematics employed plays a dominant role in obtaining the answer, and is not free of questionable assumptions. The final study in this report deals briefly with these approaches. Although the manner of seeking experimental results is more suited to elucidating the mathematical theory than obtaining intrinsic electrical strength, the two objectives are closely related.

\footnotetext{
"If the test area or volume is less than the dimensions to be expected of a flaw in the material, then it will be considered a micro volume.
} 
The Experimental Procedure

\section{Mechanical Shock Resistance and Its Relationship to Electrical Shock}

Mechanical shock resistance and its relationship to electrical shock (pulse) was observed by exploding wires embedded in four casting resins, SRIR (semi-rigid inspection resin), TIR (transformer impregnating resin), Sylgard, and Adiprene-L. This method was chosen for four reasons. First, the energy delivered to test samples of different composition would be reasonably constant for a particular capacitor voltage. Second, the stress pattern set up would be the same as that thought to occur during dielectric breakdown. Third, the exploding wire process would rapidly strain the surrounding material. And finally, the samples could be easily examined for characteristic damage after being tested.

The extent of fracture induced by the exploding wire was used as a rough indication of the ability of each material to withstand mechanical shock. Then the shock-withstanding ability of each material was compared to the electrical pulse life data and single pulse partial breakdown path length data to see if correlation existed. The electrical pulse life test was described by Milton. ${ }^{1}$ The partial breakdown path length test was essentially the same as the pulse life test except that the material was pulsed just once.

Cubical samples (Figure 1) were used to facilitate viewing of the interior; cylindrical samples would have introduced optical distortion. Gas checks were used for the high energy Adiprene-L and Sylgard tests when it was found that gas blew out of the sample ends along the wire unless the checks were used. The exploding wire was $5 \mathrm{mil}$ Therlo(Kovar), 1/2 inch long. The 32 mil copper lead-in wire was soldered to the test wire.

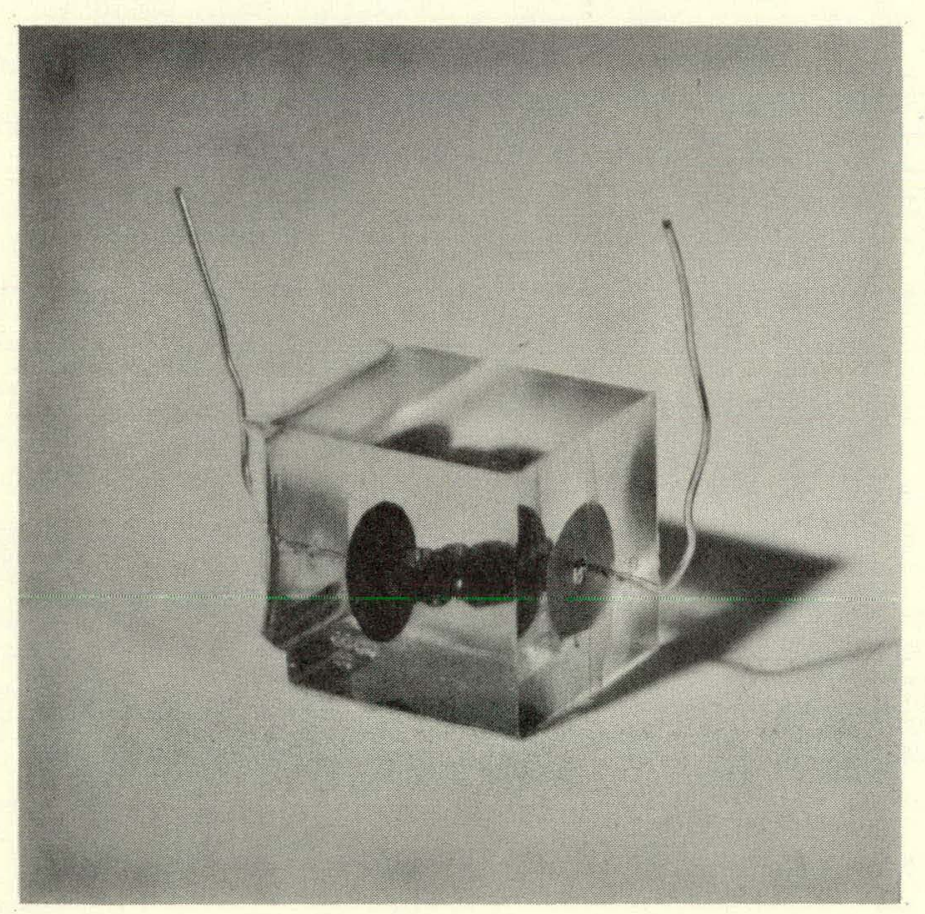

Figure 1. Exploding Wire Test Geometry With Gas Checks, Wire Previously Exploded
The basic circuit was suggested by T. J. Tucker. ${ }^{2}$ The circuit constructed for the experiment (Figure 2) was as small and robust as possible to keep resistance and induced voltage to a minimum. A $0.0467-\mathrm{ohm}$ current viewing resistor was used for accurate measurement of the current flowing through the exploding wire, and the output of the resistor was monitored by an oscilloscope. The scope trace was recorded photographically.

The resistive portion of the voltage drop across the exploding wire could not be accurately measured because of the unknown inductance of the wire under pulsed conditions; induced voltage in such a case obscures the resistive voltage drop. Thus, there was no accurate, direct means of determining the energy liberated in the sample. Instead, 


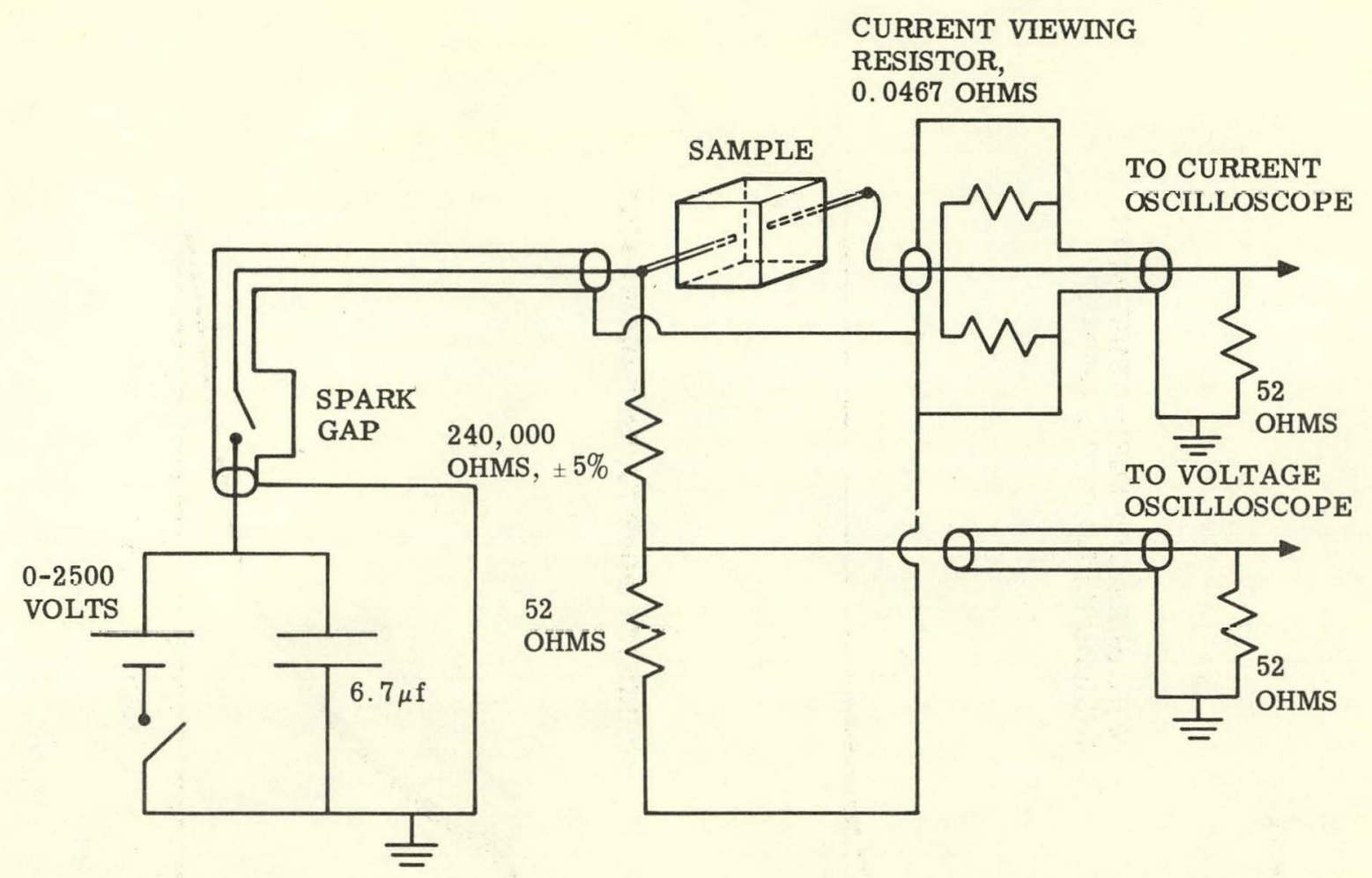

Figure 2. Schematic of Exploding Wire Circuit

voltage remaining across the capacitor after each test was measured and this measurement was also displayed on a scope and recorded on Polaroid film. Figure 3 shows a typical current and voltage trace obtained during testing. The voltage before test was indicated by a voltmeter. Thus the energy released by the capacitor to the circuit could be computed using the formula

$$
E=\frac{1}{2} C\left(v_{1}^{2}-v_{2}^{2}\right)
$$

By assuming that a certain fixed percentage of this energy was absorbed in the circuit, one could then get a general feeling for how much energy was released in the sample.

A more accurate method of determining the energy released in an exploding wire involves obtaining the resistance versus the electrical action, $\int i^{2} \mathrm{dt}$, of the wire to be electrically exploded. ${ }^{3}$ Sample leads were placed in two opposing clips, the desired capacitor voltage set, and the wire exploded. In general, low capacitor voltages were tried first, with successively higher tests following. Framing camera pictures were taken to give an idea of the velocity of fracture induced by the exploding wire. Tests were terminated when either a particular voltage resulted in the sample blowing apart, or when the limiting capacitor voltage was reached.*

\footnotetext{
* This method had not been used extensively by the investigators when this report was written.
} 


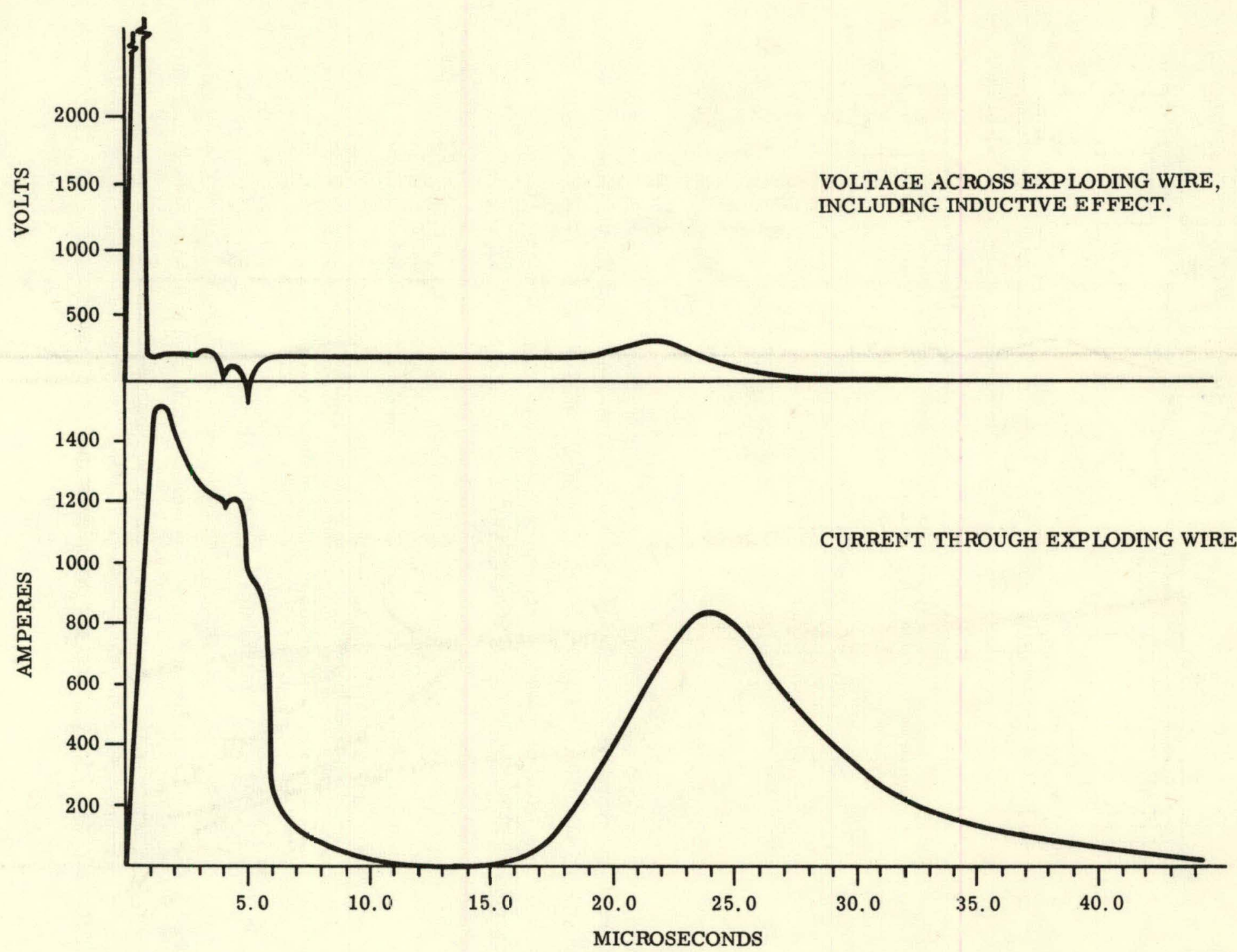

Figure 3. Typical Voltage and Current Characteristic, Obtained From Adiprene-L Tested With Gas Checks at 2000 Volts 


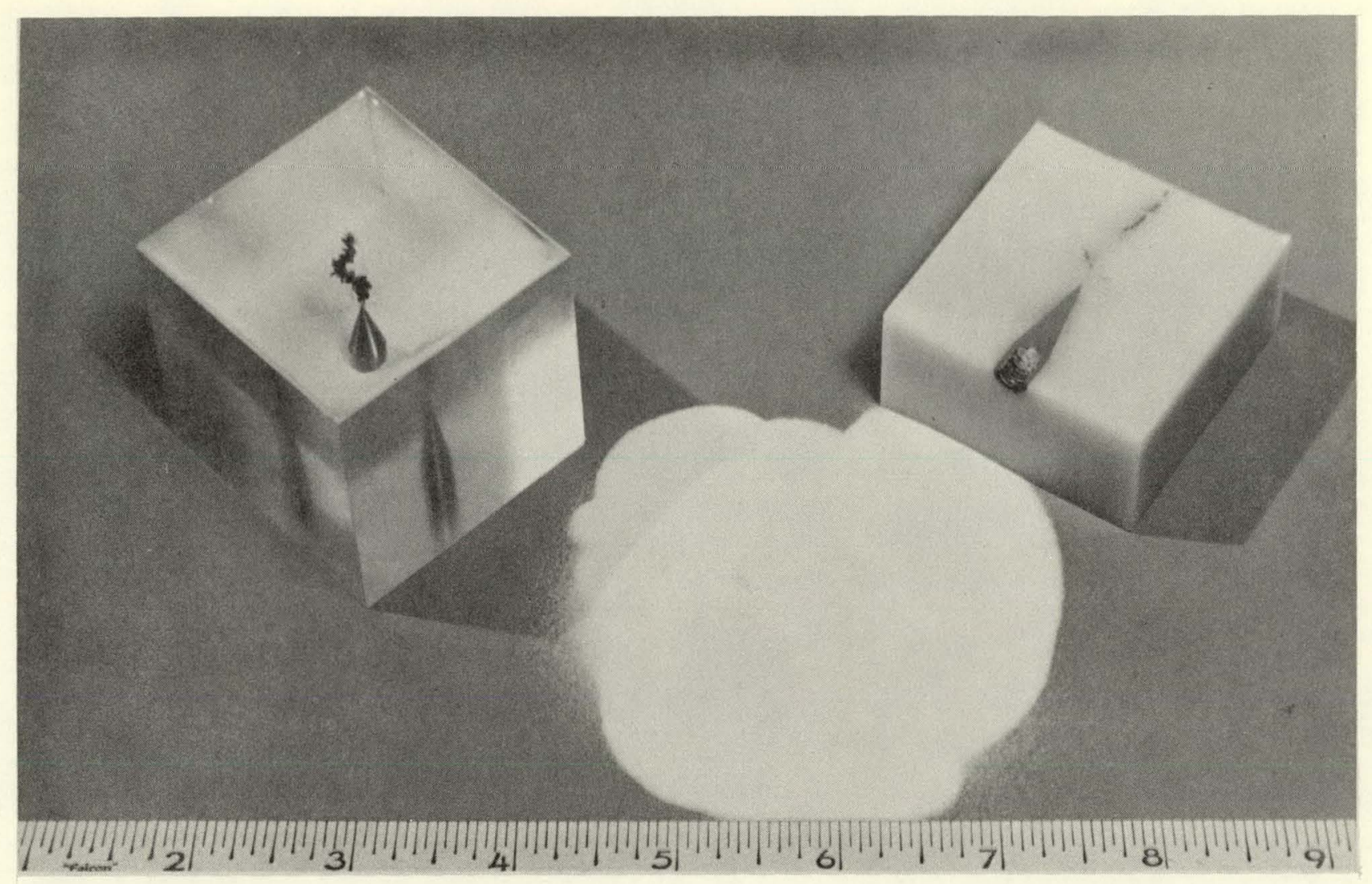

Figure 4. An Unfilled Sample and a Cross-Sectioned Filled Sample Which Have Been Tested. Also Shown is a Sample of the Gilass Filler.

\section{Effect of Fillers on Pulse Life of Epoxy Resins}

For the investigation of the effect of fillers on pulse life, solid glass spheres ranging in diameter from $10 \mu$ to $840 \mu$ were added to the uncured resin which was then thoroughly mixed and finally degassed in an evacuated chamber. This mixture was then cast into 2 -inch cubes with a conical pointed electrode located at the center of each (see Figure 4). After being cured, each cube was placed in oil to a depth of $3 / 4$ inch; electrical connection to a high voltage pulse generator was made within the oil medium. Then $10 \mu \mathrm{sec}$ pulses of $250 \mathrm{kv}$ to $400 \mathrm{kv}$ were applied to the electrode once each second until final breakdown occurred.

The resin used in this study was a polyol-modified, anhydride-cured epoxy, a clear material referred to as SRIR. * The fillers used thus far have been (1) standard soda-lime glass, (2) borosilicate glass, and (3) fused quartz (very pure silica), in both spherical and irregular particle shape, and in closely graded size distributions.

\footnotetext{
* SRIR was used in all three studies mentioned.
} 


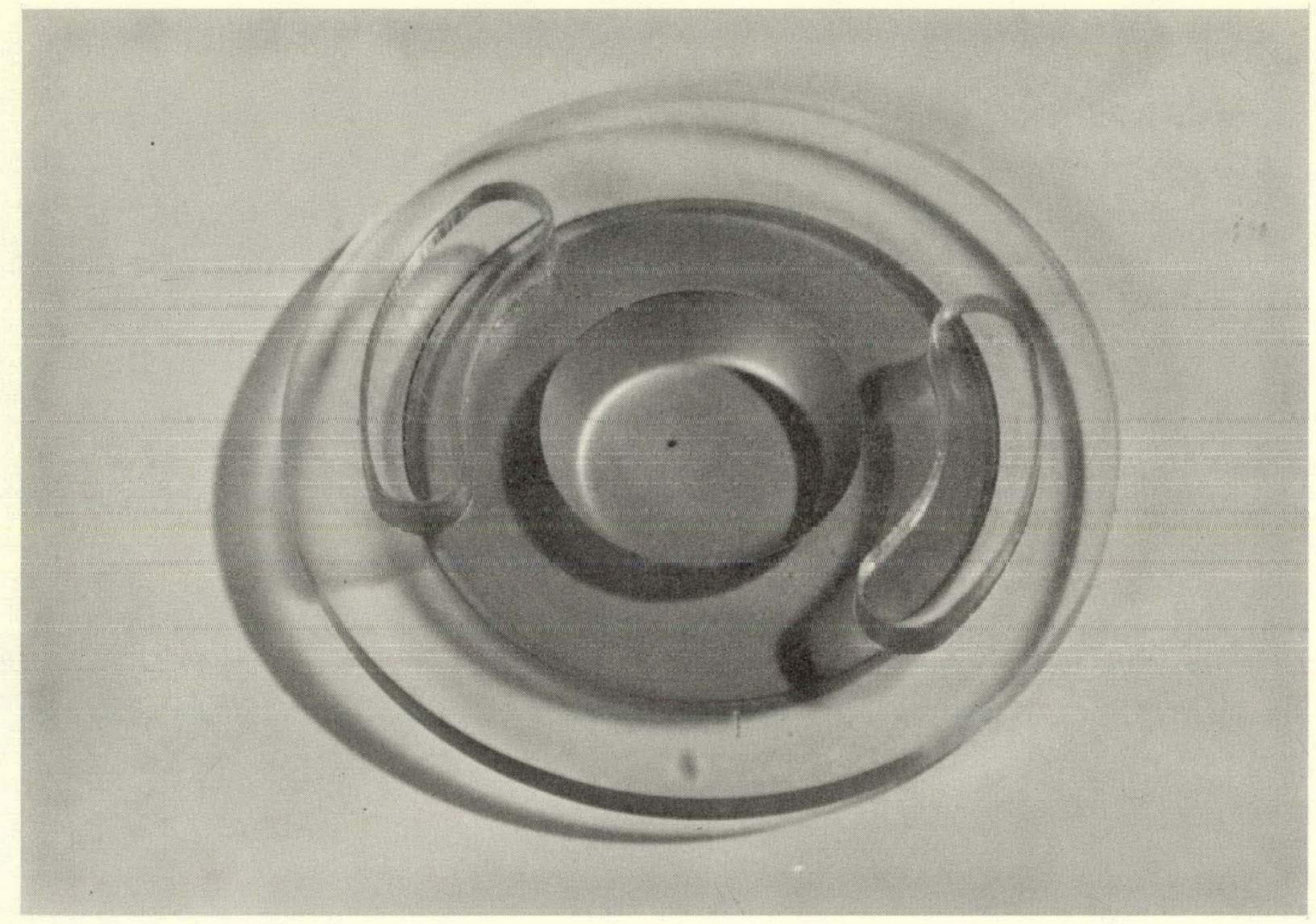

Figure 5. Contoured Dielectric Test Sample

\section{The Intrinsic Electrical Strength of an Epoxy Resin}

Two experimental approaches to the determination of the intrinsic strength of insulating materials will be considered here. The first of these methods used a sample (see Figure 5) with a test area greater than $0.25 \pi$ square inch and a thickness of 0.020 inch to 0.100 inch resulting in a volume under test of sufficient size to make a perfect sample a rare possibility. ${ }^{*}$ Hence it was expected that the breakdown would be at the weakest point of the material under test and that a single test value should not be considered an intrinsic value.

The test sample was an accurately formed equipotential surface; the field was known at every point on the surface, thus allowing calculation of the field at the point of breakdown. This feature was important in that it allowed corrected field values to be used in the statistical evaluation; sample imperfections were recognized, and thus the intrinsic strength was likely to be obtained by only one sample in a thousand or more. The sample contour was recessed and the electrode was painted on the sample so that corona was effectively eliminated.

\footnotetext{
* The sample would tend to be perfect from the material point of view if it were homogeneous, isotropic, and free of impurities and flaws.
} 


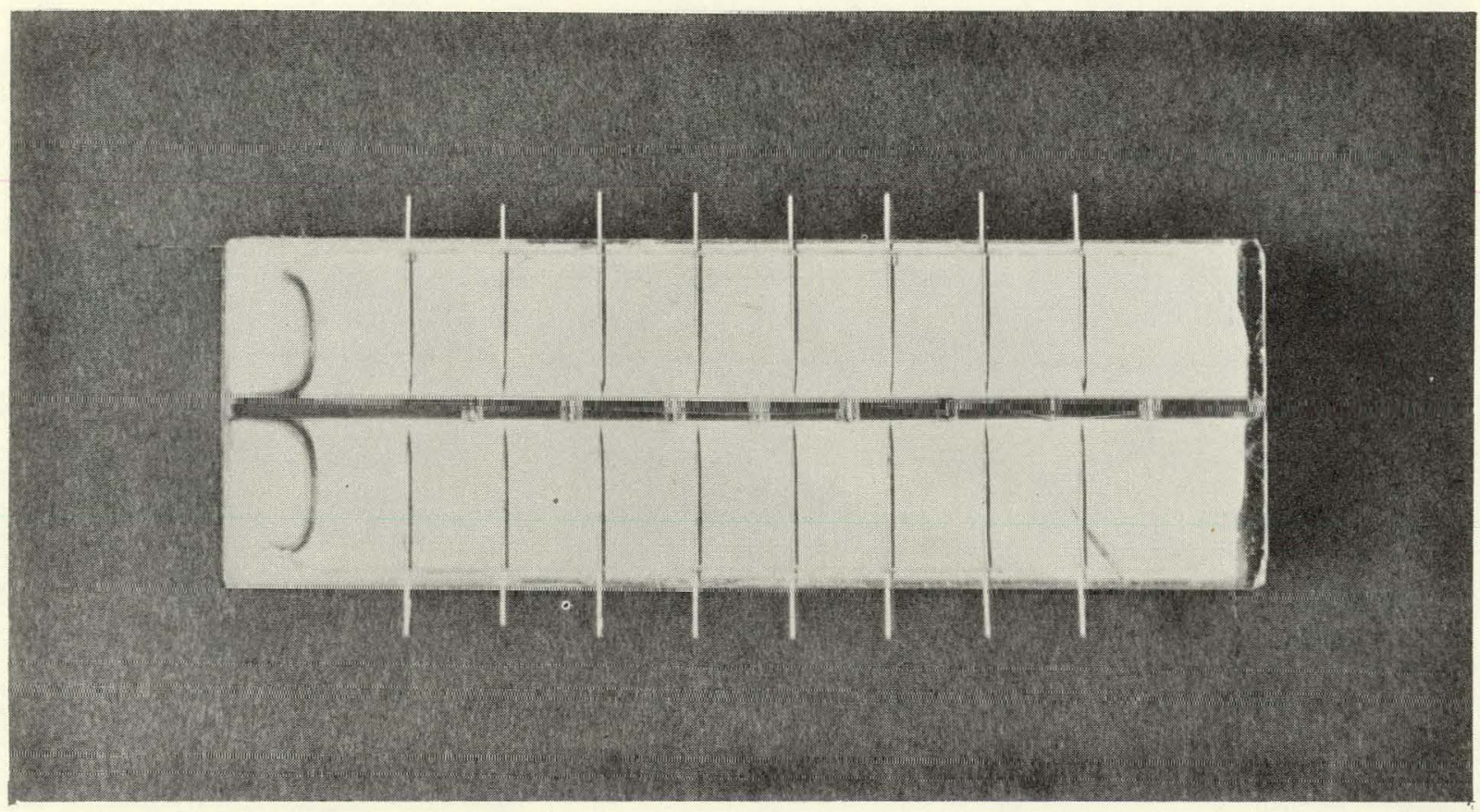

Figure 6. Sample for Pin Tests

The second method for determining intrinsic strength involved use of brass sewing pins contoured to a quadric surface by means of electrolytic etching. The radius at the tip of the pin was about $0.01 \mathrm{~mm}$ and the electrode separation was about $0.16 \mathrm{~mm}$. A very small volume of the dielectric is tested with this electrode arrangement. Figure 6 shows a typical test assembly which has 16 pins cast into a block of epoxy, together with a common ground bar.

The equation generating the surface of the pin had to be determined for each pin. A 400X photograph of the pin following the etching treatment was made and this photograph was dimensionally analyzed. The dimensions then were fitted to an equation of two variables and the coefficients were determined. These coefficients were used to determine the electrode separation and also the field. If satisfactory values for the coefficients were not found (indicating that a proper surface had not been generated), the pin under study was discarded.

Electrode distance was adjusted to the desired value by means of micrometer type "C" clamp under a calibrated microscope, before the test assembly was encapsulated with the casting resin. Following cure of the resin, the distances were checked again to observe whether any significant changes occurred as a result of the casting and curing processes. The breakdown voltage was determined experimentally and these values together with the previously determined coefficients, were used later to determine the dielectric strength of the material. 
I. The results of the exploding wire test revealed the shock resistant properties of the four materials. SRIR and TIR were the most susceptible to shock. The samples of each were blown completely apart for released capacitor energies of about 7 joules. There were few cracks formed in these two materials. However, once a crack started, it propagated to the sample boundary.

Adiprene-L and Sylgard, on the other hand, had the best and second best shock-resistance, respectively. Without gas checks, the exploding wire gas blew out around the lead wires, lessening the damage. With gas checks, both materials were exposed to the maximum energy that the capacitor could deliver, about 16 joules, without blowing apart. For a released capacitor energy of about 13 joules, the Adiprene and Sylgard samples had damage extending around the wire axis in about a $1 / 32$-inch and $1 / 8$-inch radius, respectively.

Both Adiprene-L and Sylgard had a great many fracture planes. No one plane seemed to go much farther than the next. Also, the planes appeared to have a semicircular boundary, with the center and diameter on the wire, almost as if there had been shock nuclei along the wire with each nucleus causing a semicircular fracture. The failure mechanism in both Adiprene- $\mathrm{L}$ and Sylgard seemed to be tension with the fracture planes occurring parallel to the wire and extending radically outward (Figures 7 and 8 ).

SRIR and TIR, on the other hand, seemed to have no definite failure mode. Their fracture planes in some instances would be radial indicating tensile failure. In other instances, the fracture planes would curve gradually, indicating shear failure, although they generally started out in a radial manner. Figure 9 shows a photomicrograph of a wire exploded in SRIR.

Framing camera pictures of wires exploding in the four materials indicate an order of magnitude difference in crack propagation for identical released energies. SRIR and TIR showed the fastest propagation, on the order of $0.5 \mathrm{~mm} / \mu \mathrm{sec}$, for released capacitor energies of 13 joules, whereas Sylgard had a rate of about $0.08 \mathrm{~mm} / \mu \mathrm{sec}$. Adiprene was even lower. SRIR and TIR started cracking immediately upon the start of wire explosion, whereas Sylgard and Adiprene appeared to expand fairly uniformly around the wire for a while. Figures 10 and 11 show framing camera pictures of wires exploding in SRIR and TIR.

The results to date of this portion of the test program are given in Table I, along with some electrieal data. ${ }^{4}$ Table I shows that SRIR has the longest pulse life and the shortest partial breakdown path length of any of the four materials tested, and yet SRIR together with TIR have the poorest shock resistance and the highest fracture velocity.

The only obvious conclusion from the data was that shock resistance is inversely correlated with pulse life and partial breakdown path length for these materials, even though the inverse correlation does not hold exactly for pulse life.

It was felt that the data inversion between pulse life and partial breakdown path length for Sylgard and Adiprene-L might be due to differences in heating within the materials during repeated high voltage pulsing. The thermal diffusivity, defined as $\mathrm{K} / \mathrm{C}_{\mathrm{p}} \rho$, where $\mathrm{K}=$ thermal conductivity, $\mathrm{C}_{\mathrm{p}}=\mathrm{specific}$ heat 


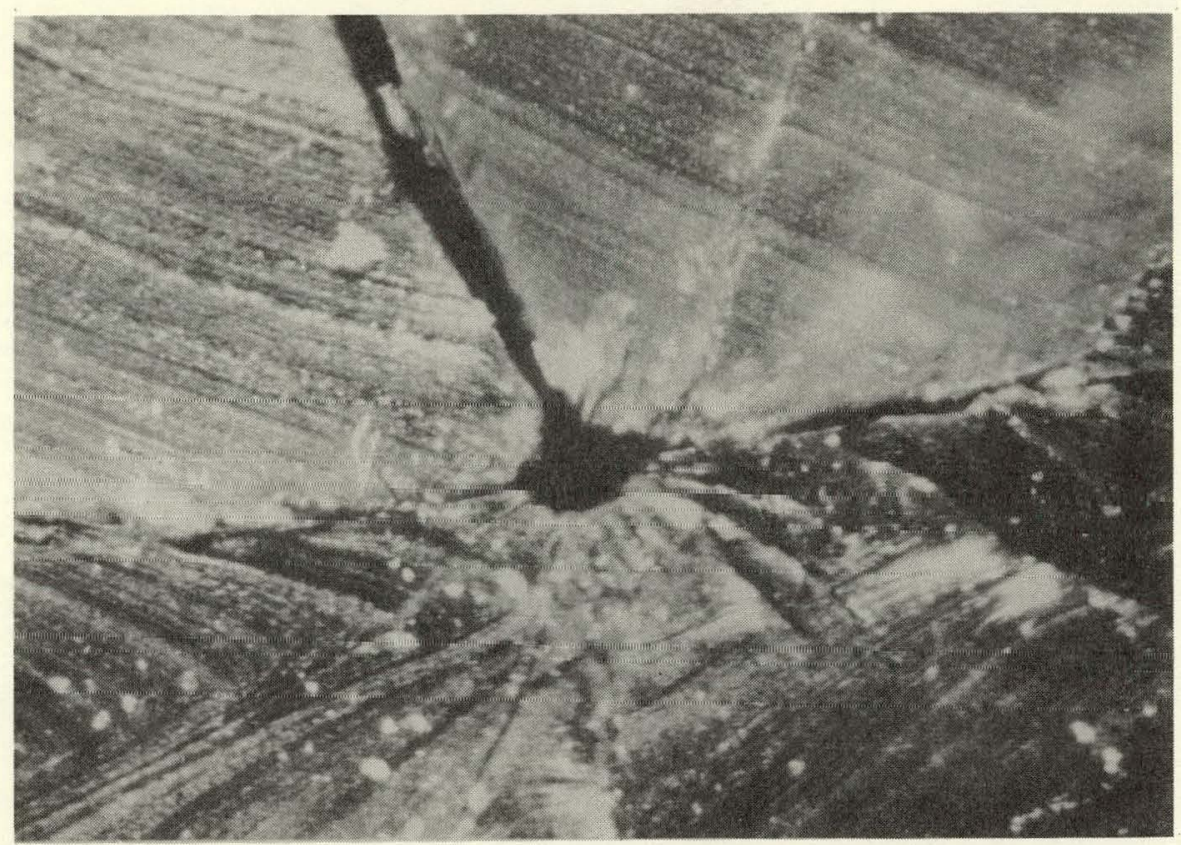

Figure 7. Exploded Wire in Sylgard 182, 35X

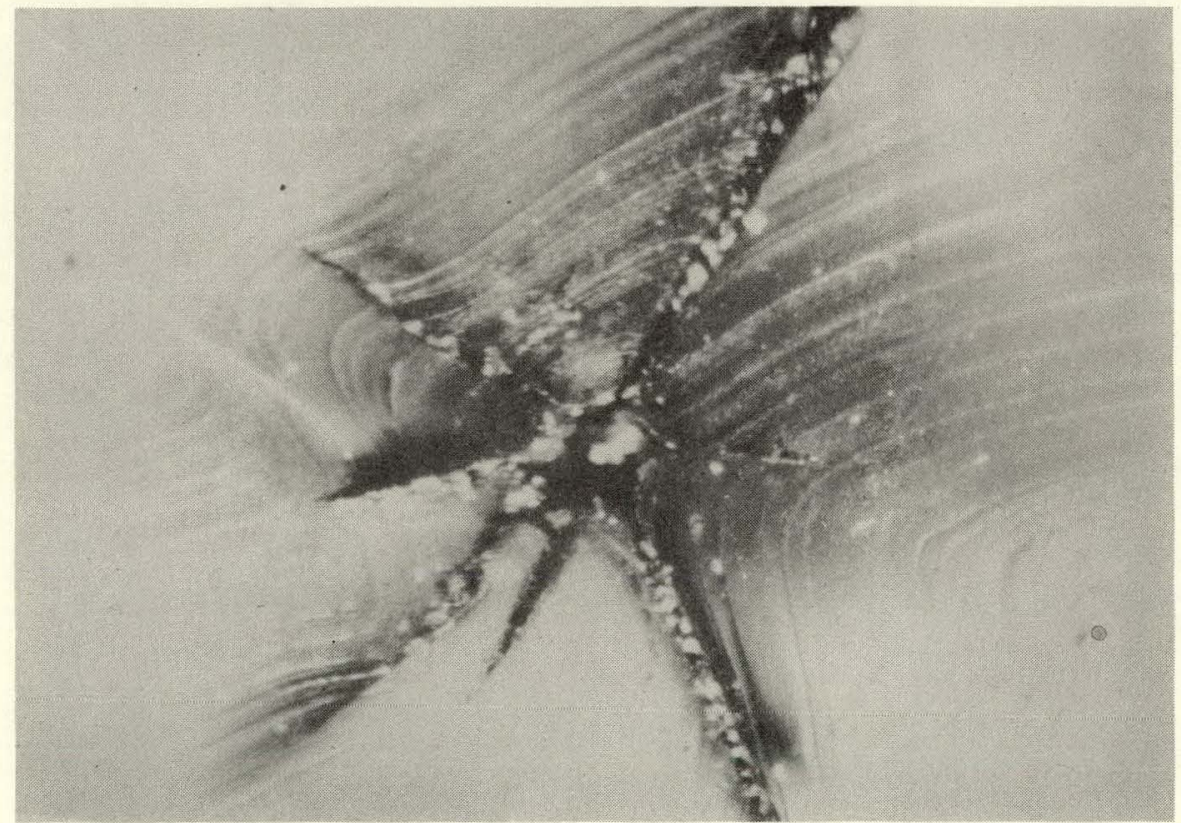

Figure 8. Exploded Wire in Adiprene-L, 35X 


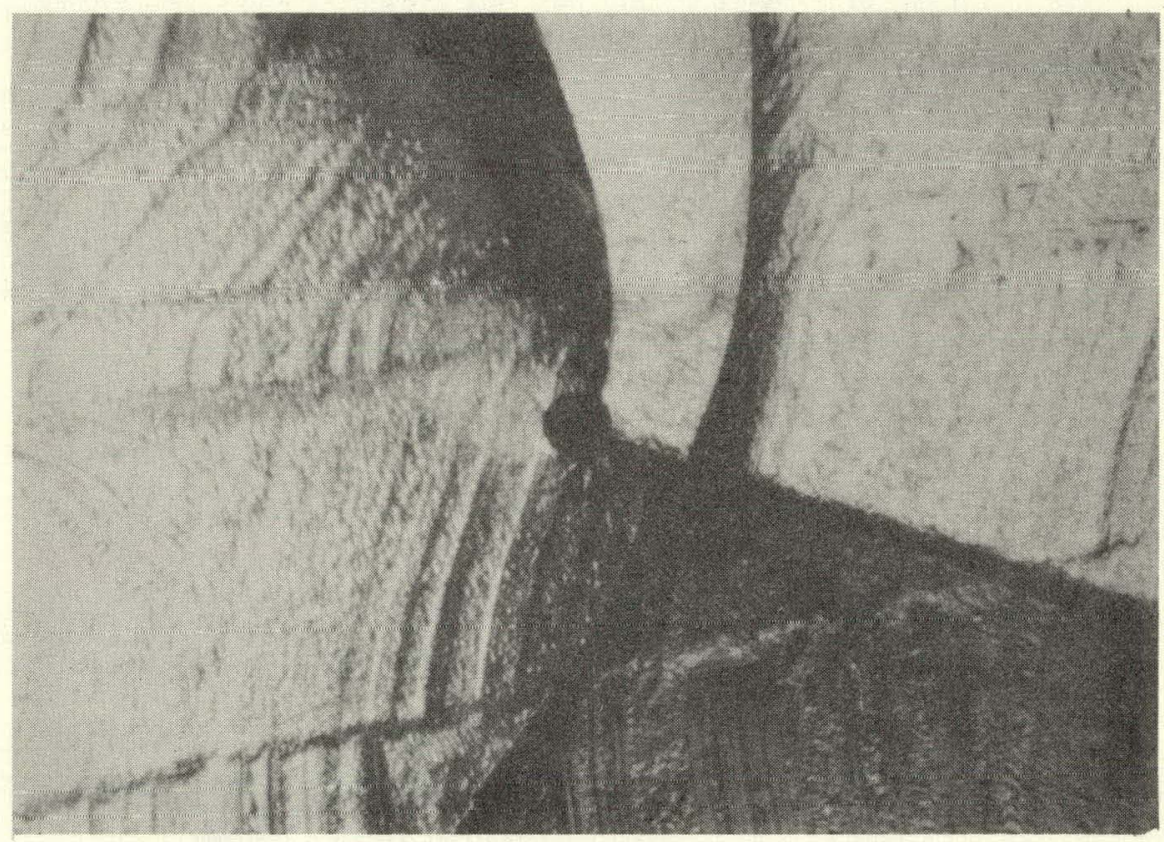

Figure 9. Exploded Wire in SRIR, 35X 


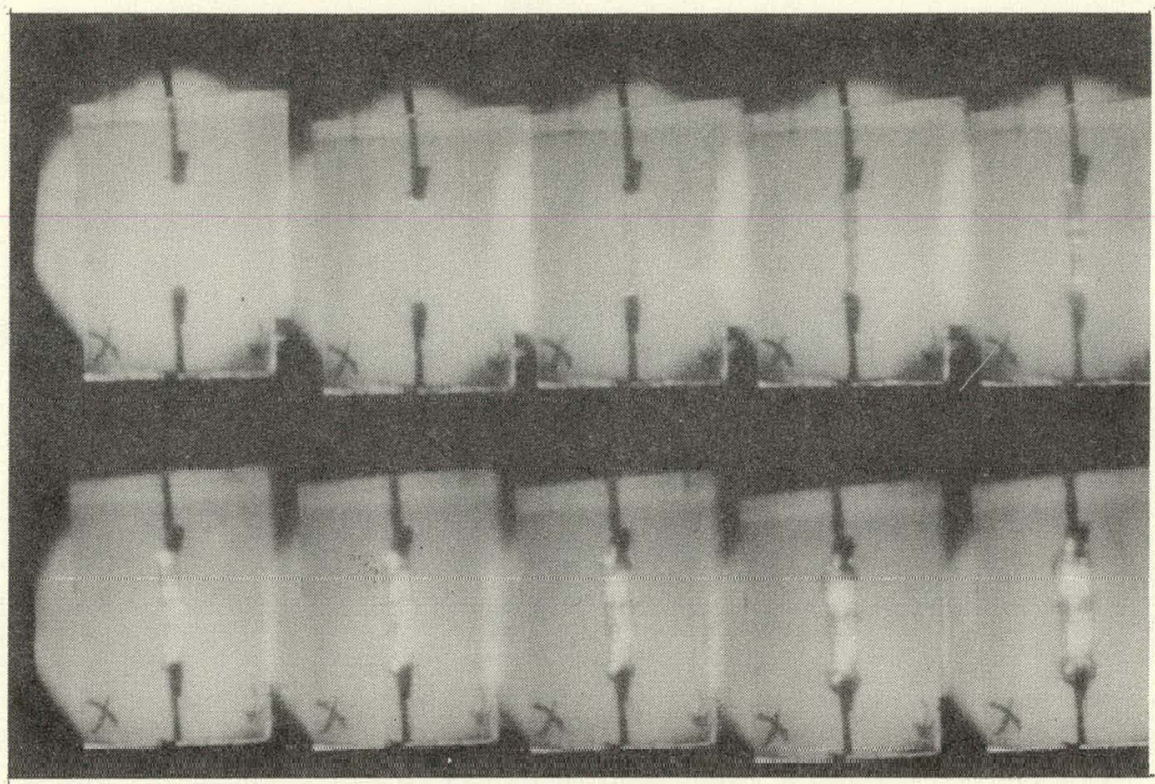

Figure 10. Wire Exploding in Sylgard 182. Framing Rate $=250 \times 10^{3} / \mathrm{sec}$

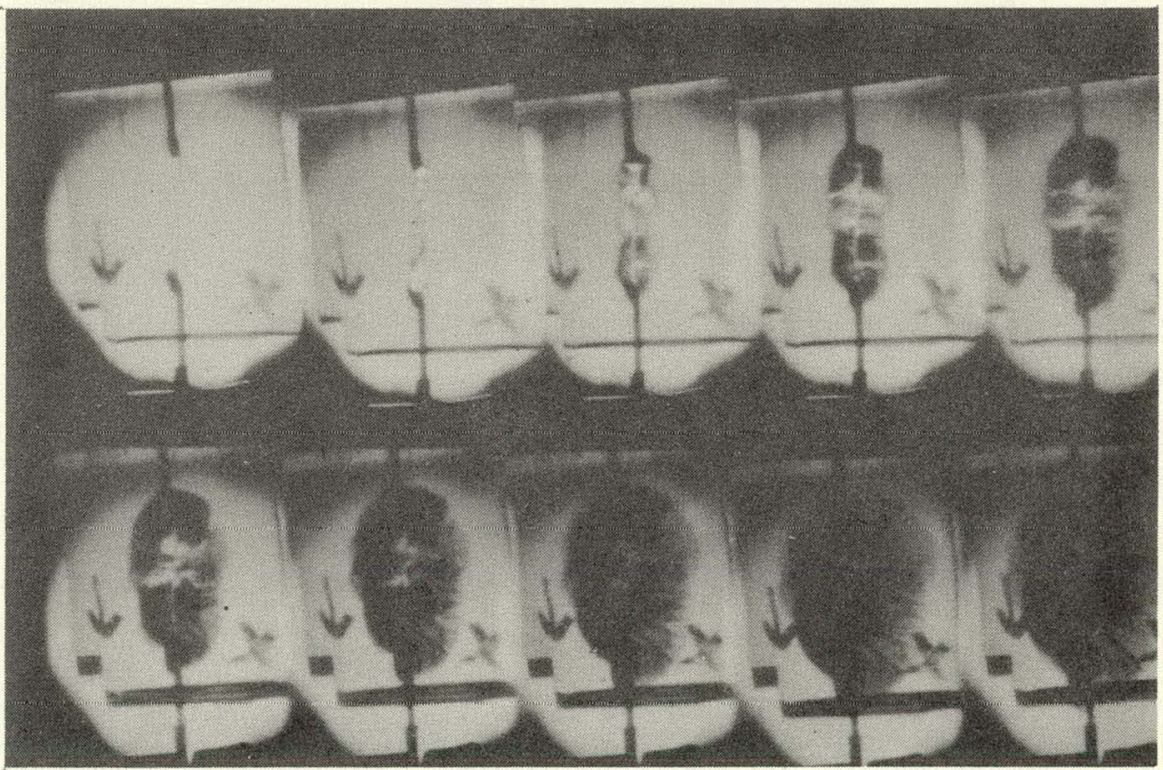

Figure 11. Wire Exploding in SRIR. Framing Rate $=250 \times 10^{3} / \mathrm{sec}$ 
TABLE I

Breakdown Data for Four Materials

\begin{tabular}{|c|c|c|c|c|}
\hline Material & SRIR & TIR & Sylgard & Adiprene-L \\
\hline $\begin{array}{l}\text { Electrical pulse } \\
\text { life at } 200 \mathrm{kv}\end{array}$ & $>4300$ & $>2500$ & $<20$ & $<200$ \\
\hline Shock resistance & Poor & Poor & Good & Excellent \\
\hline $\begin{array}{l}\text { Single pulse } \\
\text { partial breakdown } \\
\text { path length at } \\
236 \mathrm{kv} \text {, in inches }\end{array}$ & $0.25-0.38$ & $0.25-0.38$ & $0.5-0.75$ & $\begin{array}{l}\text { Complete } \\
\text { breakdown }\end{array}$ \\
\hline $\begin{array}{l}\text { Fracture velocity } \\
\text { in mm/ } \mu \mathrm{sec} \text { for } \\
\text { released capacitor } \\
\text { energy of } 13 \text { joules }\end{array}$ & 0.5 & 0.5 & 0.08 & $<0.08$ \\
\hline
\end{tabular}

and $\rho=$ density, gives a good indication of how quickly a material will diffuse a thermal gradient within itself. A material with high diffusivity should withstand repeated high voltage pulsing well because it can quickly dissipate any high temperatures produced by a partial breakdown. A low diffusivity material, however, will tend to retain these high temperatures, thus weakening its resistance to further pulsing. Thus it was felt that although Adiprene-L suffered a complete breakdown during the partial breakdown path length test, perhaps its diffusivity was higher than Sylgard's and that it might therefore have a longer pulse life at lower voltages. To test the above explanation, the thermal diffusivity was experimentally determined for the four materials. The data appears in Figure 12. As can be seen, the diffusivities of Sylgard and Adiprene-L are almost identical. The data inversion is obviously due to some other cause.

Since there does seem to be an inverse correlation between shock resistance and electrical pulse resistance, it would seem that poor shock resistance, or dynamic brittleness, is important in the makeup of insulators having good high-voltage pulse resistance. Perhaps the rapid failure associated with this brittleness quickly absorbs the released energy from a partial breakdown. To use a more specific and physical interpretation, perhaps the rapid failure quickly relieves the high temperature and pressure in a suddenly formed partial breakdown filament. This rapid relief would reduce the charge density in the filament and thus would reduce the field at the filament tip. Naturally such a result would promote high voltage resistance.

II. The results of the filler study show that the pulse life of these samples is an exponential function of the applied electrode voltage V, probably something like

$$
\text { Pulse life } \approx \frac{V_{0}}{V} e^{a\left(v_{0}-V\right)} \text { pulses, }
$$

where for these materials $275 \leq \mathrm{V}_{\mathrm{o}} \leq 325$, the extrapolated single pulse voltage intercept (Figure 13), is in kilovolts and $0.10 \leq a \leq 0.33$ is a function of the filler, assuming its larger values when filler is added. 


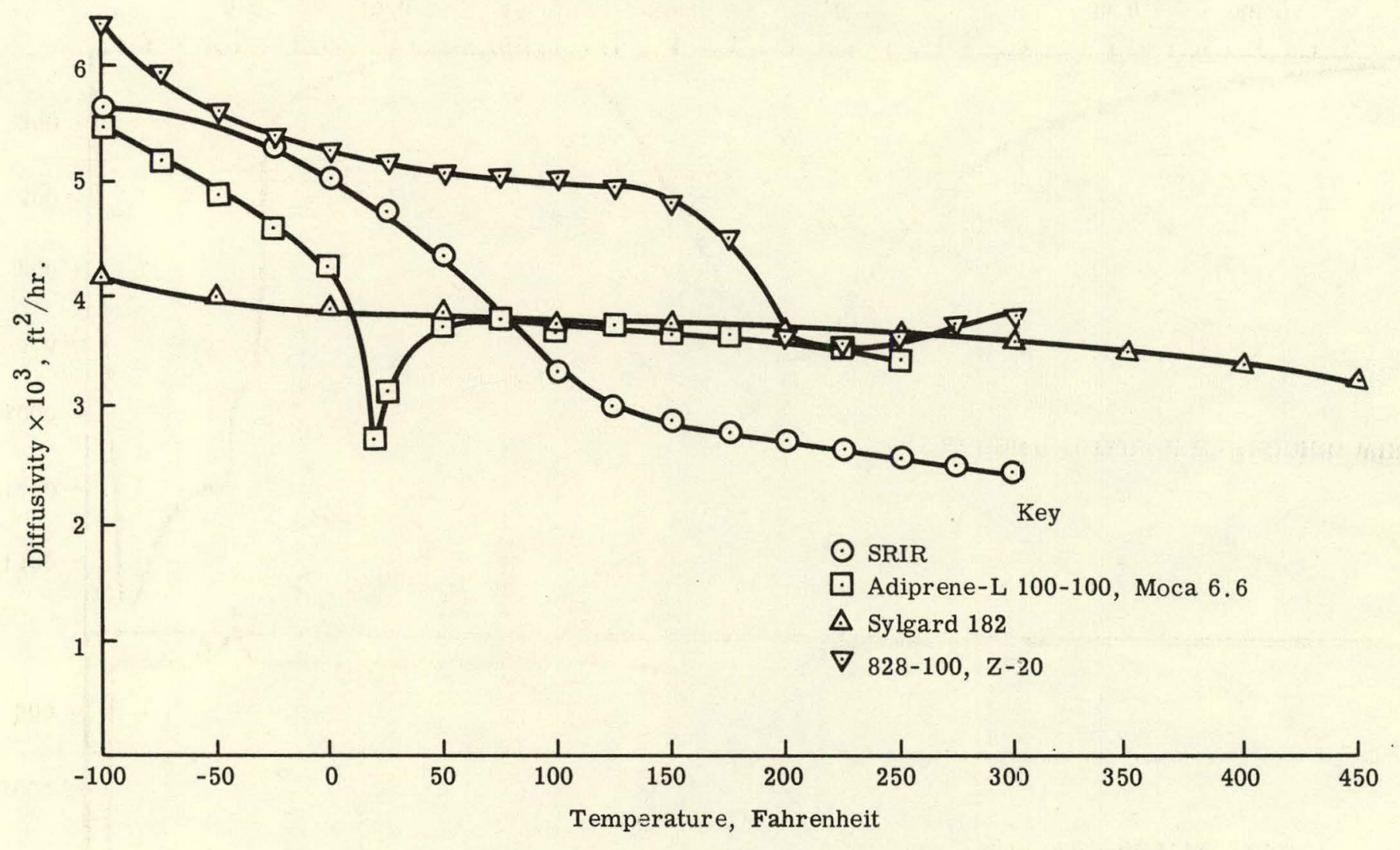

Figure 12. Thermal Diffusivity Versus Temperature for Four Casting Resins 


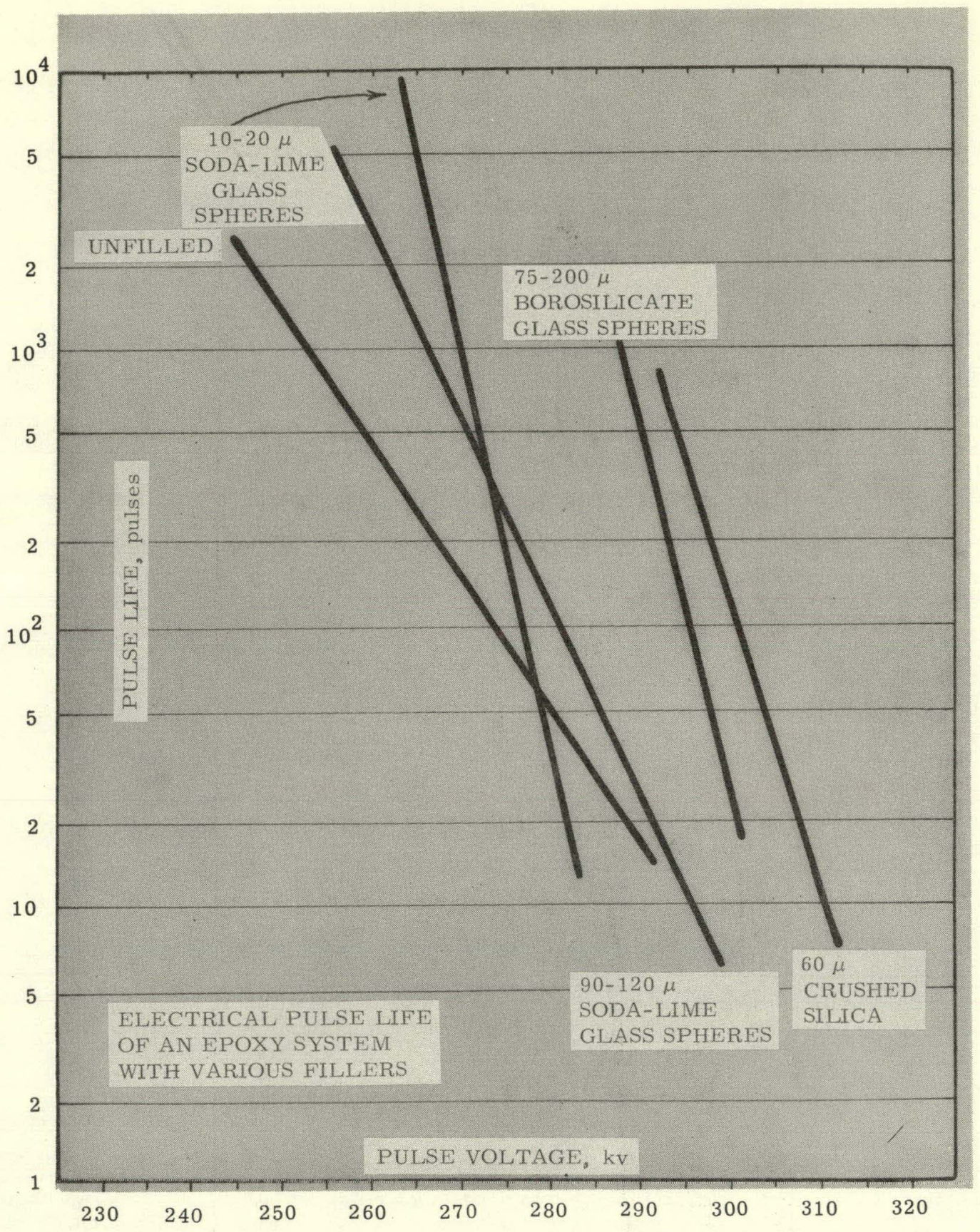

Figure 13. Electrical Pulse Results for the Filler Study

The graph in Figure 13 shows the effect of filler for some filled mixtures. The graphs of the function favor the data which represent the more resistant specimens. (These materials are now being prepared in thick sheets so that their pulse breakdown strengths (method similar to ASTM D149-61) may be determined and correlated with the above data.) Thus fillers of the type tested do seem to improve the pulse life of the resins used. 
III. Figure 14 represents a graph of the electrical pulse breakdown values of contoured samples of SRIR. The intrinsic strength appears to be at least $15.0 \mathrm{kv} / \mathrm{mil}$. The mode value is about $3.6 \mathrm{kv} / \mathrm{mil}$ and the mean value is about $4.3 \mathrm{kv} / \mathrm{mil}$. This graph also shows that if $10 \mathrm{samples}$ were tested, one of the 10 would break down at a value of at least $7 \mathrm{kv} / \mathrm{mil}$. Further, the graph shows that the lowest value to be expected for the SRIR is about $0.4 \mathrm{kv} / \mathrm{mil}$.

The following field equation was used to calculate the field at breakdown on the contoured samples: ${ }^{5}$

$$
\underline{E}=\frac{P_{0}}{A \pi}\left(\frac{e^{x} \sin y}{\left(1+e^{2 x}+2 e^{x} \cos y\right)} \underline{i}-\frac{1+e^{x} \cos y}{\left(1+e^{2 x}+2 e^{x} \cos y\right)} \underline{j}\right),
$$

where $\mathrm{P}_{0}$ is the voltage applied at breakdown, $\mathrm{A}$ is a scaling factor, $\mathrm{y}$ is a constant, and $\mathrm{x}$ is $\mathrm{related}$ to the breakdown location.

The value of $15 \mathrm{kv} / \mathrm{mil}$ may be expressed as $6 \times 10^{6} \mathrm{v} / \mathrm{cm}$ which is beginning to be in the intrinsic range considered to be about $10^{7} \mathrm{v} / \mathrm{cm}$.

The field equation obtained by Milton used to calculate the field at breakdown on the conoidal surfaces is

$$
E=\frac{2 P}{\pi}\left(\frac{x^{2} b^{2}}{a^{2}}+x^{2}-a^{2}\right)^{-1 / 2}
$$

where $a, b$, and $x$ are from the equation describing the surface. Another field equation, obtained by Eyring, ${ }^{6}$ maybe used to calculate the field at breakdown on a conoidal surface:

$$
E=-4 P_{\circ}\left[\frac{u}{v^{2}\left[\log \frac{8 u}{v^{2}}+\log u\right]}\right] \text {, }
$$

where $\mathrm{u}$ is electrode separation and $\mathrm{v}$ is a function of the electrode radius.

For the pins in use (Figure 6), the two field equations have been solved. It was found that if Milton's equation was used, the field was obtained by multiplying the potential at breakdown by 19.2 . If Eyring's equation was used, the multiplication factor was 60 . Differences between the two equations were more significant if the geometry and spacing of the pins was changed significantly. This has not been evaluated at present, however.

Results of the contour tests should show an intrinsic strength for SRIR of at least $15.0 \mathrm{kv} / \mathrm{mil}$ or $600 \mathrm{kv} / \mathrm{mm}$. Correcting for a thinner thickness and smaller test area as used in the pin test, it is reasonable to expect $800 \mathrm{kv} / \mathrm{mm}$ as an intrinsic strength.

For the geometry and spacing mentioned in the experimental procedure, Milton's method predicted a breakdown voltage of

$$
P_{0}=\frac{800}{19.2}=41.7 \mathrm{kv}
$$




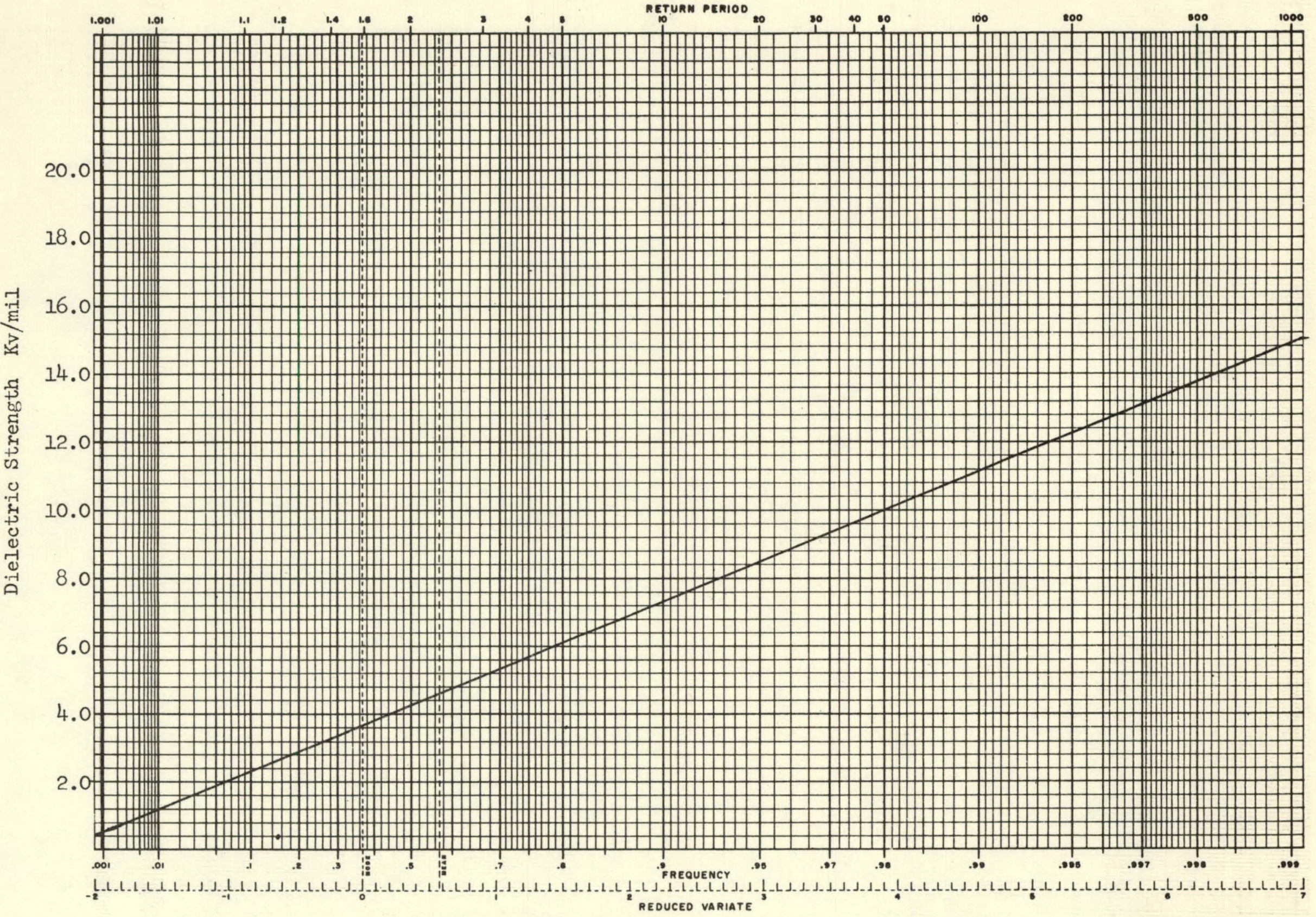

Figure 14. Distribution of Pulse Dielectric Strengths for SRIR. Contoured Sample, 0.030 Inch Thick 
Eyring's method predicted a breakdown voltage of

$$
P_{0}=\frac{800}{60}=13.3 \mathrm{kv}
$$

Actual obtained values were about $39 \mathrm{kv}$, thus the relative errors were factors of about 1.07 and 2.93 , respectively.

Conclusions

Results of the filler study indicate the increased influence of fillers for the longer pulse lives at lower voltages. The results also imply the ineffectiveness of fillers in the vicinity of the one-pulse breakdown threshold. Since the presence of the fillers does indeed impair the growth of small trees which eventually take part in catastrophic breakdown, the filler study supports the mechanical breakdown theory; but fillers cannot absorb sufficient energy to prevent the powerful, higher-inception voltage arc from forming. Finally, interpretation of the filler study results must be made with respect to other type mechanisms, especially in view of the exploding wire tests.

Results of the exploding wire test indicate that sudden cracking during a partial breakdown process may influence the continuation of that process. The rapid failure associated with the better insulators tested may quickly relieve the high temperature and pressure in a suddenly-formed partial breakdown filament. This rapid relief would reduce the charge density in the filament and would thus reduce the field at the filament tip. Such a result would seem to promote high-voltage pulse resistance.

Initial results of the intrinsic strength study are promising in that reasonable predictions of breakdown voltage were made for drastic changes in electrode geometry. It appears that considerable improvement in the mathematical theory and the test method is possible. Thus there is hope that with more work on this approach, close predictions of failure voltage for a given situation may be obtained. As a step in this direction, some pins are being made which fit a desired quadric equation quite closely. Results will be obtained for varying electrode distances thus enabling better evaluation of the two field equations.

List of References

1. Milton, O., The Electrical Impulse Strength Testing of High Polymers, SCTM 38-63(11).

2. Tucker, T. J., "Square Wave Generator For the Study of Exploding Wires, " Rev. of Sci. Inst., 31, No. 2, 165, (1960).

3. Halpin, W. J. and Hendricks, R. E., The Use of Pressure Bars and Plates for the Investigation of

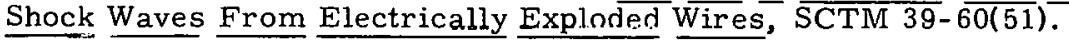

4. Milton, O., The Electrical Impulse Strength Testing of High Polymers, SCTM 28-63(11).

5. Milton, O., A Recessed Rogowski Electrode for Electric Strength Testing, to be published by ASTM, 1965 Proceedings, December 1965, SC-DC-64-372.

6. Eyring, C. F., Mackeown, S. S., and Millikan, R. A., "Field Currents From Points," Physical Review, 31, (May 1928). 